\title{
Sık Ventriküler Erken Vuruların Sebep Olduğu Dekompanse Kalp Yetmezliği
}

\author{
Frequent Ventricular Premature Complex-Induced Decompensated Heart Failure
}

\author{
Hüseyin Ede' , Veysel Kutay Vurgun², Ali Timuçin Altın², Bașar Candemir², Ömer Akyürek², \\ Çetin Erol ${ }^{2}$
}

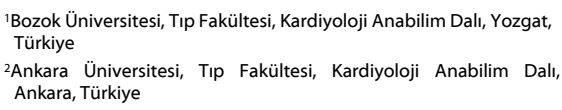

Bozok Üniversitesi, Tıp Fakültesi, Kardiyoloji Anabilim Dalı, Yozgat, Türkiye

ªnkara Üniversitesi, Tıp Fakültesi, Kardiyoloji Anabilim Dalı, Ankara, Türkiye

Geliș Tarihi: 31.03.2015• Kabul Tarihi: 27.05.2015

\section{illetișim:}

Yrd. Doç. Dr. Hüseyin EDE

Cep: +905056711104

Tel: $\quad+903542127060$

Faks: +90 3542123739

E-posta: huseyinede@gmail.com

Bozok Üniversitesi, Tıp Fakültesi, Kardiyoloji Anabilim Dalı,

Adnan Menderes Bulvarı No:44 66200 Yozgat, Türkiye

Asemptomatik ventriküler erken atım, hem yapısal kalp hastalığı olan hem de olmayan kișilerde en sık görülen aritmi tipidir. Sık ventriküler erken atım normal kalp yapısı olan hastalarda uzun dönemde sol ventrikül yetmezliğine yol açabilir. Biz, burada, acil servise akut kalp yetmezliği kliniği ile bașvuran ve kateter ablasyonu sonrası șikâyet ve bulguları gerileyen ventriküler erken atım ilișkili kardiyomiyopati olgusunu sunduk.

Anahtar Sözcükler: Akut Kalp Yetmezliği, Kardiyomiyopati, Kateter Ablasyonu, Ventriküler Erken Atım

Asymptomatic premature ventricular beats are most common presentation form of arrhythmia observed in patients with or without structural heart disease. In long term, frequent premature ventricular beats can lead left ventricule failure in structurally normal heart. Here, we reported a case of premature ventricular complex-induced cardiomyopathy who applied to emergency department with acute heart failure and recovered promptly after catheter ablation of related arrhytmic focus.

Key Words: Acute Heart Failure, Cardiomyopathy, Catheter Ablation, Ventricular Premature Complex

Ventriküler aritmiler kardivoloji pratiğinde sıkça karşılaştı̆̆ımız aritmiler olup asemptomatik seyredebileceği gibi hemodinamik bozulmaya yol açabilir ve/veya doğrudan ani kardiyak ölümle de sonuçlanabilir (1). Ventriküler erken atım (VEA) kardiyoloji pratiğinde sıkça görülmekle birlikte ventriküler taşikardi/flutter ve ventriküler fibrilasyon nadiren karşılaştığımız ventriküler aritmilerdir (1).

Asemptomatik ventriküler erken atım, hem yapısal kalp hastalığ olan hem de olmayan kişilerde en sık görülen aritmi şeklidir (2). Artmış VEA sıklığının; hipertansiyon, dislipidemi, diabetes mellitus gibi geleneksel kardiyovasküler risk faktörleri ve koroner arter hastalığı ile ilişkili olduğu bildirilmiştir (3). Konjestif kalp yetmezliği ve sol ventrikül disfonksiyonu olan hastalarda da s1klikla görülen VEA, bu hasta grubunda artmış mortaliteyle ilişkilidir (4-6).
Ventriküler erken atımın kendisi de normal kalp yapisı olan hastalarda uzun dönemde sol ventrikül yetmezliğine yol açabilir (7). Normal kișilerde 24 saatlik ritim kayıtlarında toplam atımın \%10'undan fazla VEA olmas1 efor dispnesine yol açabilirken, \%20'sinden fazla VEA'nın olması sol kalp yetmezliği ile sonuçlanabilir $(3,8)$. Hastaların VEA'ya bağlı şikâyetlerinin başlangiciyla kardiyomiyopati arasindaki geçen süre yıllar alabildiği gibi bazen de bu uzun süreç asemptomatik seyredebilir. Bunun için takip ve gerekirse tedavi planı yapmak oldukça önemlidir (9). Sık VEA'nın tedavisinde sıklıkla antiaritmik ilaçlar ve kateter ablasyonu önerilmektedir. Kateter ablasyonu sonras1 VEA ilişkili kardiyomiyopatinin düzelme belirtileri 1 hafta gibi kısa bir süre sonra bașlamakta, altıncı aydan sonra da belirgin düzelme görülebilmektedir $(10,11)$. 
Biz, burada acil servise akut kalp yetmezliği kliniği ile başvuran ve kateter ablasyonu sonrası şikâyet ve bulguları gerileyen sık ventriküler erken atım ilişkili kardiyomiyopati olgusunu sunduk.

\section{OLGU}

Acil servise progresif artış gösteren nefes darlığ1 ile başvuran 51 yaşındaki kadın hastanın anamnezinde bilinen kardiyovasküler risk faktörü yoktu. Hastanın son altı aydır olan çarpıntı ve son bir aydır giderek ar$\tan$ nefes darlığı şikayeti vardı. Hasta başvurusunda ortopneik, taşikardik, takipneik olup kan basinc1 140/90 mmHg idi. Hastanın yap1lan kardiyak muayenesinde ventriküler ekstrasistol, apekste $2 / 6$ şiddetinde sistolik üfürüm, solunum muayenesinde her iki akciğerde bazallerde krepitan raller mevcuttu, diğer sistem muayeneleri normaldi. Çekilen elektrokardiyografide (EKG); ritim sinüs, hız $96 \mathrm{atım} / \mathrm{dk}$, sağ ventrikül çıkış yolu kaynaklı (RVOT) bigemine VEA ve V1-6 derivasyonlarda $T$ dalgası negatifliğ mevcuttu. QTc değeri $420 \mathrm{msn}$ olup akut koroner sendrom düşündürecek ST segment değişikliği yoktu. Takip troponin değerleri negatif idi. Yapılan ekokardiyografik incelemede; sol ventrikül diyastol sonu çap (LVDSÇ): $53 \mathrm{~mm}$, sol ventrikül sistol sonu çap (LVSSÇ): $44 \mathrm{~mm}$, sol atriyum çap1 (LA): 47 $\mathrm{mm}$, sol ventrikül ejeksiyon fraksiyonu (LVEF): \%34, interventiküler septum kalınlığ1 (IVSd): $10 \mathrm{~mm}$, arka duvar kalınlığı (PWd): $10 \mathrm{~mm}$ olarak ölçüldü, 1. derece mitral yetmezlik (MY) saptandı. Hastanın troponin değerlerinin negatif olmas1 ve ekokardiyografi bulguları nedeniyle hastada miyokardit düşünülmedi. Mevcut şikâyet ve bulgulara dayanarak akut pulmoner ödem düșünülen hastanın șikâyetleri uygulanan intravenöz diüretik, oksijen ve intravenöz nitrogliserin tedavisi ile geriledi. Hastaya elektif şartlarda bakılan elektrolit, kreatinin, hemogram ve TSH değerleri normal sinırlarda idi. Hastada elektif şartlarda tekrarlanan EKG'de
RVOT kaynaklı bigemine VEA saptanması ve anamnezde çarpintı olması nedeniyle 24 saatlik Holter kaydı yapıldı. Yirmi dört saatlik kayıtta bazal ritim sinüs, ortalama kalp hız1 74 atım/dakika olup toplam 107.136 atımin 46.068'i (\%43) ventriküler erken atımd, eşlik eden ventriküler veya supraventriküler taşikardi atağ1 yoktu. Sık bigemine VEA ve düşük LVEF olan hastanın düşük LVEF nedenini saptama ve tedavi amaciyla aritmi servisine yatırild.

Hastada olası koroner iskemiyi ekarte etmek için diagnostik koroner anjiyografi uygulandi. Koroner anjiyografide normal koroner arterler saptand. Sik ventriküler erken atımı ve kardiyomiyopatisi olan hastaya elektrofizyolojik çalışma (EPS) yapildı. EPS'de bazal siklus uzunluğu $830 \mathrm{msn}, \mathrm{AH}$ : 85msn, HV: 45msn idi. Sağ ventrikül apeks ve çıkış yolundan yapılan programlı pacing ile ventriküler taşikardi indüklenmedi. VEA odağı sağ ventrikül çıkış yolu, pulmoner kapak altı posterior bölgede lokalize edildi ve bu bölgeye RF ablasyonu uygulandi. Ablasyon sonrası VEA' lar kayboldu. Kateter ablasyonu sonrası hastanın çarpıntı şikayeti ortadan kalktı, monitorizasyonda VEA izlenmedi. Hastanın EPS' de VEA odağının olması, başar1lı ablasyon sonrası ekokardiyografi bulgularının düzelmesi, VEA sıklığının azalması üzerine s1k VEA' ya bağlı kardiyomiyopati geliştiği düşünülerek hastaya ICD uygulamasından vazgeçildi ve medikal takip karar1 verildi.

Tablo 1: Hastanın takip ekokardiyografik ölçümleri gösterilmiştir.

\begin{tabular}{lllllllll}
\hline & $\begin{array}{l}\text { LVDSÇ } \\
(\mathrm{mm})\end{array}$ & $\begin{array}{l}\text { LVSSÇ } \\
(\mathrm{mm})\end{array}$ & $\begin{array}{l}\text { LVEF } \\
(\%)\end{array}$ & $\begin{array}{l}\text { LA } \\
\text { Çapı } \\
(\mathrm{mm})\end{array}$ & $\begin{array}{l}\text { IVSd } \\
(\mathrm{mm})\end{array}$ & $\begin{array}{l}\text { Mitral } \\
\text { E/A }\end{array}$ & $\begin{array}{l}\text { PASB } \\
(\mathrm{mmHg})\end{array}$ & MY \\
\hline ișlem & 53 & 44 & 34 & 47 & 10 & $25 / 65$ & 35 & 1. derece \\
öncesi & & & & & & & & minimal \\
1.ay & 49 & 33 & 57 & 40 & 10 & $35 / 62$ & 30 & minimal \\
6. ay & 50 & 32 & 57 & 41 & 10 & $33 / 55$ & 30 & yok \\
12.ay & 51 & 32 & 59 & 42 & 10 & $30 / 50$ & 30 & yok \\
18. ay & 50 & 31 & 59 & 40 & 10 & $36 / 58$ & 27 & yok \\
24. ay & 47 & 30 & 60 & 40 & 10 & $32 / 48$ & 28 & \\
\hline
\end{tabular}

LA: Sol atriyum, LVDSÇ: Sol ventrikül diyastol sonu çap, LVEF: Sol ventrikül ejeksiyon fraksiyonu, LVSSÇ: Sol ventrikül sistol sonu çap, MY: Mitral yetmezlik, PASB: Pulmoner arter sistolik basınç
Hastanin takiplerinde sol ventrikül sistolik fonksiyonlarının iyileştiği görüldü. Ablasyon sonrasi birinci ayda yapilan ekokardiyografide LVDSÇ:49 mm, LVSSÇ: $33 \mathrm{~mm}$, LA:40 mm, LVEF:\%57, IVSd:10 mm, PWd:10 mm olarak ölçüldü, minimal MY saptandı. Hastaya işlemden bir ay sonra yapilan 24 saatlik Holter kaydında bazal ritim sinüs, ortalama kalp hiz1 63 olup toplam 90.739 atımin 726 's1 $(\% 0,8)$ ventriküler erken atımdı, eşlik eden ventriküler veya supraventriküler taşikardi atağ1 yoktu. Hasta son kontrolüne ablasyon sonras1 24 . ayda geldi. Yapilan ekokardiyografide LVDSÇ:47 mm, LVSSÇ:30 $\mathrm{mm}$, LA: $40 \mathrm{~mm}$, LVEF:\%60, IVSd:10 mm, PWd:10 mm olarak ölçüldü, mitral yetmezlik saptanmad1 (Tablo 1). Hasta halen bisoprolol tedavisi altında semptomsuz takip edilmektedir.

\section{TARTIȘMA}

Ventriküler erken atım, yapısal kalp hastalığ1 olan veya olmayan hastalarda görülebilir (1). Çoğunlukla asemptomatik seyredebildiği gibi sıklığ1nın artması durumunda kardiyomiyopatiye yol açabilir $(6,7)$. Artmış VEA sıklığı koroner arter hastalığı, hipertansiyon, dislipidemi ve diabetes mellitus gibi risk faktörleri ile ilișkilidir $(3,4)$. Ayrıca artmıș VEA sıklığ1, LV sistolik yetmezliği ve konjestif kalp yetmezliği olan hastalarda artmıș mortalite ile ilișkilidir (3-5). Biz; burada, akut pulmoner ödem tablosuyla başvuran, s1k bigemine VEA, düşük LVEF ile baş- 
vuran ve öncelikle ICD uygulaması için yatırılan fakat başarılı VEA ablasyonu sonrası bulguları düzelen kardiyomiyopati olgusunu sunduk.

Yapılan bir çalışmada multiform morfolojiye sahip ventriküler erken atımlı hastalarda kardiyovasküler olay (konjestif kalp yetmezliği, miyokard enfarktüsü, inme) sıklığının daha fazla olduğu gösterilmiştir (3). Yapılan başka bir çalışmada da sağ ventrikül kaynaklı VEA'ların LVEF'yi daha fazla düşürdügü görülmüştür (12). Bizim vakamızın işlem öncesi elektrokardiyografik kayıtlarında uniform, RVOT kaynaklı bigemine VEA mevcuttu ve 24 saatlik Holter kayıtlarında toplam 107.136 atımin 46.068'i (\%43) ventriküler erken atımdı. Literatürde de \%20'den fazla VEA sıklığının kardiyomiyopatiye yol açabileceği belirtilmiştir (7, 8, 12). Fakat VEA sıklığının belli bir seviyenin üzerinde olduğu her klinik durum kardiyomiyopati ile sonuçlanmamaktadir. Asemptomatik geçebilen uzun latent periyodlar bildirilmiştir. Çarpint1, güçlü kalp vurusu gibi semptom başlangıcıla kardiyomiyopati gelişimi arasındaki süre de değişkendir (9). Ancak semptomatik hastalarda çarpıntı başlangıcıyla tıbbi müdahale arasındaki süre uzadikça kardiyomiyopati gelişim riskinin arttığ1 gösterilmiștir (9). Bu konuda yapılan çalışma sayısı sınırlidir. Bizim olgumuzda semptom başlangıcı ile tanı konulma arasındaki süre yaklaşık altı ay olup bu süre literatür verisi ile uyumludur.

Sık VEA ve düşük sol ventrikül ejeksiyonu ile başvuran hastalarda açılı̆̆ga kavuşturulması gereken bir diğer husus da hangisinin daha önce geliştiğidir. LV sistolik disfonksiyonunun kendisinin VEA sıklığını arttırdığ1 bilinmektedir. Bu durumda tedavi, varsa iskemiyi ortadan kaldırmak, medikal tedaviyi yoğunlaştırmak, ani kalp ölümü açısından risk değerlendirmesi yapıp gerekirse ICD uygulanması şeklinde olurken, doğrudan sık VEA'ya bağlı kardiyomiyopati varlığında tedavi VEA odağının kateter ablasyon yönte- miyle ortadan kaldırılmasıdır (13). Dolaysiyla düşük ejeksiyon fraksiyonu ile başvuran tüm hastalarda her iki senaryo da göz önüne alınmalıdır. Aksi takdirde hastalar uygun olmayan ICD implantasyonu ile karşı karşıya kalabilir. Bu ayrımı yaparken risk faktörlerinin ve/veya eşlik eden ciddi koroner arter hastalığının varlığ yardımcı olabilir. Bu durumların varllğı, LV disfonksiyonuna bağlı sık VEA lehinedir. Biz de olgumuzu değerlendirirken öncelikle s1k bigemine VEA, düșük EF ve semptomatik olmasi nedeniyle ICD açısından değerlendirmek üzere yatırdık. Fakat hastada kardiyovasküler risk faktörünün olmamas1, yapilan koroner anjiyografinin normal olmasi, yapilan EPS'de VEA odağının saptanmasi, başarılı ablasyon sonrası LVEF'nin hızla düzelmesi VEA sıklığına bağlı kardiyomiyopati tanisinı desteklemekteydi.

Literatürde VEA ilişkili kardiyomiyopati bildirilmiş olmakla beraber, asemptomatik VEA siklığ1 göz önüne alındığında, az sayıda kardiyomiyopati gelişmesi ilginçtir. Yapılan bir çalışmada R222Q SCN5A mutasyonu olan hastalarda VEA ve dilate kardiyomiyopati sıklığının arttığ1 gösterilmiştir (14). Kardiyomiyopati gelişmiş hastalara bu açıdan genetik test yapmanın önemi ile ilgili yeni çalışmalara ihtiyaç vardır.

S1k VEA's1 olan hastalarda göz önünde bulundurulması gereken bir diğer hususta, ekokardiyografik LVEF ölçümünün sik ekstrasistol nedeniyle olması gerekenden düşük ölçülmesidir. Bunun önüne geçmek için EKG eşliğinde birbirini takip eden iki sinüs atımı referans alınarak modifiye Simpson yöntemi ile ölçüm yapılmalıdır (9). Biz, bu olguda birbirinden bağımsız iki kardiyolog tarafindan ölçümleri tekrarlattık, yanı sıra ICD implantasyonu kararı için sadece EPS öncesi değil ablasyon sonraki takiplerindeki LVEF ölçümlerini de değerlendirmeye aldık. Dolaysiyla takiplerinde yapilan ekokardiyografik ve MUGA ile LVEF ölçümleri normal s1- nurlarda olduğundan ICD uygulanmasından vazgeçtik.

Kateter ablasyonu sonrası sol ventrikül sistolik fonksiyonlarının toparlanması bir hafta gibi kısa bir süre içerisinde başlamakta ve ortalama altınc1 ayda belirgin düzelme görülmektedir (11). Bizim vakamızın takiplerinde de birinci ayın sonunda ejeksiyon fraksiyonunda \%23 artış görülmüş. Birinci aydan sonraki tüm LVEF değerleri normal sınırlarda saptanmıştır.

Sonuç olarak, ICD implantasyonu adayı hastaların, VEA nedeniyle LVEF değerlerinin düşük ölçülebileceği ve eğer ölçümler doğru yapılmışsa da ablasyon sonras1 LVEF'nun düzelmesinin zaman alabileceği düşünülerek, kateter ablasyonu sonrası LVEF ölçümlerinde acele edilmemeli, ölçümler uygun biçimde bağımsız klinisyenler tarafından tekrarlanmalıdır. Düşük LVEF'lu, normal koroner arterlere sahip s1k VEA'lı hastalarda ICD implantasyonu için acele edilmemeli, kateter ablasyonu seçeneği öncelikle düşülmelidir. Ablasyon tedavisi sonras1 hastalar yeni LVEF ölçümü ile tekrar değerlendirilmelidir. Böylelikle hastalar uygunsuz ICD implantasyonu riski ile karşılaşmamış olurlar.

\section{SONUÇ}

Uzun süreli sık ventriküler erken atım dilate kardiyomiyopati ile sonuçlanabilir. Sol dal bloğu morfolojisinde sık ventriküler erken atımı olan, kardiyovasküler risk faktörü olmayan, normal koroner arterlere sahip düşük ejeksiyon fraksiyonlu hastalarda, ventriküler erken atım ilișkili kardiyomiyopati düşünülmelidir. $\mathrm{Bu}$ hastalarda aritmi odağının kateter ablasyonu ile ablasyonu en uygun tedavi seçeneğidir. Bu hastalarda ICD implantasyonu kararı vermeden önce, kateter ablasyonu denenmeli ve ablasyon sonrasi LVEF ölçümleri mutlaka tekrarlanmalı, gerekirse nükleer görüntüleme ile $\mathrm{EF}$ değerlendirilmelidir. 


\section{KAYNAKLAR}

1- Katritsis DG, Siontis GC, Camm AJ. Prognostic significance of ambulatory ECG monitoring for ventricular arrhythmias. Prog Cardiovasc Dis. 2013;56:133-142.

2- Simpson RJ Jr, Cascio WE, Schreiner PJ, et al. Prevalence of premature ventricular contractions in a population of African American and white men and women: The Atherosclerosis Risk In Communities (ARIC) study. Am Heart J 2002;143:535-540.

3- Ephrem G, Levine M, Friedmann P, Schweitzer P. The prognostic significance of frequency and morphology of premature ventricular complexes during ambulatory holter monitoring. Ann Noninvasive Electrocardiol. 2013;18:118-125

4- Bikkina M, Larson MG, Levy D. Prognostic implications of asymptomatic ventricular arrhythmias: The Framingham Heart Study. Ann Intern Med 1992;117:990996.

5- Sheldon SH, Gard JJ, Asirvatham SJ. Premature Ventricular Contractions and Non-sustained Ventricular Tachycardia: Association with Sudden Cardiac Death, Risk Stratification, and Management Stra- tegies. Indian Pacing Electrophysiol J. 2010;10:357-371.

6- Duffee DF, Shen WK, Smith HC. Suppression of frequent premature ventricular contractions and improvement of left ventricular function in patients with presumed idiopathic dilated cardiomyopathy. Mayo Clin Proc 1998;73:430-433.

7- Lee GK, Klarich KW, Grogan M, Cha YM. Premature ventricular contractioninduced cardiomyopathy: a treatable condition. Circ Arrhythm Electrophysiol. 2012;5:229-236

8- Winkens RA, Höppener PF, Kragten JA, et al.Are premature ventricular contractions always harmless? Eur J Gen Pract. 2013 Nov 28. [Epub ahead of print]

9- Yokokawa M, Kim HM, Good E, et al. Relation of symptoms and symptom duration to premature ventricular complexinduced cardiomyopathy. Heart Rhythm. 2012;9:92- 95.

10- Hasdemir C, Kartal Y, Simsek E ve ark. Time course of recovery of left ventricular systolic dysfunction in patients with premature ventricular contractioninduced cardiomyopathy. Pacing Clin Electrophysiol. 2013;36:612-617.
11- Yokokawa M, Good E, Crawford T, Chugh A, Pelosi F Jr, Latchamsetty R, Jongnarangsin K, Armstrong W, Ghanbari H, Oral H, Morady F, Bogun F. Recovery from left ventricular dysfunction after ablation of frequent premature ventricular complexes. Heart Rhythm. 2013;10:172-175.

12- Del Carpio Munoz F, Syed FF, Noheria A, et al. Characteristics of premature ventricular complexes as correlates of reduced left ventricular systolic function: study of the burden, duration, coupling interval, morphology and site of origin of PVCs. J Cardiovasc Electrophysiol. 2011;22:791-798.

13- Chugh SS, Shen WK, Luria DM, et al. First evidence of premature ventricular complex-induced cardiomyopathy: A potentially reversible cause of heart failure. J Cardiovasc Electrophysiol 2000;11: 328 329

14- Mann SA, Castro ML, Ohanian M, Guo G, Zodgekar P, Sheu A et al. R222Q SCN5A mutation is associated with reversible ventricular ectopy and dilated cardiomyopathy. J Am Coll Cardiol. 2012;60:1566-1573 